\title{
COMPARATIVE ANALYSIS OF SOIL HEAVY METAL POLLUTION ON DIFFERENT ROADS: A CASE STUDY IN A TYPICAL INDUSTRIAL CITY OF CHINA
}

\author{
ZHANG, J. ${ }^{1,2^{*}}-$ YAO, D. ${ }^{1}$ \\ ${ }^{1}$ School of Earth and Environment, Anhui University of Science and Technology, Huainan, \\ Anhui 232001, P. R. China \\ ${ }^{2}$ Wanjiang University of Technology, Ma'anshan, Anhui 243031, P. R. China \\ *Corresponding author:Zhang, $J$. \\ e-mail: szxyzj@sina.cn; phone: +86-555-522-6142; fax: +86-555-522-2777
}

(Received $2^{\text {nd }}$ Jul 2019; accepted $16^{\text {th }}$ Oct 2019)

\begin{abstract}
A total of 22 surface soil samples beside three different types of roads (trunk road, sub-trunk road and branch road) collected in Ma'anshan City, Anhui Province, China, were analyzed by inductively coupled plasma-atomic emission spectrometry (ICP-AES) and multivariate statistics. Besides, spatial distribution characteristics analysis was employed to identify the possible sources. The results indicate that the average concentrations of heavy metals following in the order of $\mathrm{Mn}>\mathrm{Pb}>\mathrm{Co}>\mathrm{Cr}>\mathrm{As}>\mathrm{Cd}$, and $\mathrm{Cr}$ content in the sub-trunk road are much lower than that in the trunk road and branch road. Geoaccumulation index shows that heavy metal pollution exists beside urban roads. Moreover, Cd pollution is the most serious, while $\mathrm{Co}$ and $\mathrm{Pb}$ are at a high pollution level. Potential ecological risk index shows that $\mathrm{Cd}$ poses a severe ecological risk; $\mathrm{Pb}$ and $\mathrm{Co}$ reach the medium ecological risk degree. Furthermore, two principal components (PC1 and PC2) of the heavy metal elements have been extracted by factor analysis, and the cluster analysis was consistent with the factor analysis. Based on spatial distribution characteristics, two sources have been identified: $\mathrm{PC} 1(\mathrm{~Pb}, \mathrm{Mn}, \mathrm{Co})$ are contributed mainly by industrial pollution, and $\mathrm{PC} 2(\mathrm{Cd}, \mathrm{As}, \mathrm{Cr})$ are primarily influenced by traffic pollution.
\end{abstract}

Keywords: trunk road, sub-trunk road, branch road, pollution assessment, spatial distribution characteristics, multivariate statistical

\section{Introduction}

With the development of the automobile industry and transportation in China, the motorized travel mode of the public has experienced transformation from motorcycle to automobile, and the transportation structure has also undergone fundamental changes, making urban life increasingly convenient. According to statistics from the traffic management bureau of China's ministry of public security, by the end of the 2015 year, there were 279 million vehicles in the country, including 172 million automobiles. In 2015, the number of newly registered cars reached 23.85 million, and the net increase possessions was 17.81 million. However, the rapid development of roads and traffic also brings about a series of environmental pollution problems. For example, particulate matter containing heavy metals discharged by motor vehicles directly deposited in the road dust, or through wet and dry sedimentation deposited in the soil on both sides of the road, resulting in the accumulation of heavy metals in the soil and dust on both sides of the road. Especially in the current situation of poor vehicle emission performance and poor maintenance, heavy metal pollution problem is more prominent (Guo et al., 2008). Moreover, heavy metal is highly toxic and easy to accumulate in the soil, yet challenging to migrate and degrade. If the concentrations exceed a certain level, there will be higher biological toxicity. Once the soil is contaminated by heavy metals, it is 
challenging to recover, causing serious damage to human body, environment, and even the whole food chain (Reza, et al., 2015; Hafeez, et al., 2019).

It is significant to clean the environment so as to avoid their entrance into the food chain because it is essential for protecting the health of animals and human beings. However, it is more realistic to understand the pollution status first, and then the sources of heavy metals, because not all of the heavy metals are released by anthropogenic activities, but they can also be produced by natural weathering processes of crust materials (Hashim, et al., 2011).

Pollution of soil in the current world is a major concern of the government and environment scientists, because of the importance of the soil for the survival and development of human society. Therefore, it is of great significance to analyze the pollution status of heavy metal elements in the soil along the traffic lines. Previous studies on heavy metals in soils on both sides of urban roads mainly focused on elements content, distribution characteristics, pollution status and ecological risk assessment (Afanasyeva, et al., 2019; Komendova, et al., 2018; Billah, et al., 2018; Sun, et al., 2015). However, there are few reports on the comparative study of soil heavy metal pollution besides different urban roads, especially in industrial cities. In this investigation, we selected trunk roads, sub-trunk roads and branch roads for systematic sampling and testing analysis in Ma'anshan city, a typical industrial city. In order to provide a scientific basis for the prevention and treatment of heavy metal pollution caused by highway traffic.

\section{Materials and methods}

\section{Study area}

Ma'anshan City is a steel industrial city that has risen since the late 1950s. It is located on the south bank of the lower Yangtze River and in the eastern part of Anhui Province, China. The longitude is from $118^{\circ} 21^{\prime} 38^{\prime \prime}$ to $118^{\circ} 52^{\prime} 44^{\prime \prime}$, and the latitude is from $31^{\circ} 46^{\prime} 42^{\prime \prime}$ to $31^{\circ} 17^{\prime} 26^{\prime \prime}$. Influenced by the humid climate of the northern subtropical monsoon, the city has an annual average precipitation of $1100 \mathrm{~mm}$, and an annual average temperature of 15.7 degrees (centigrade). In 2015, the city's registered population was 2.277 million, and the urban resident population was 880,000. Ma'anshan City is located in the middle and lower reaches of the Yangtze River polymetallic metallogenic belt. This area is rich in mineral resources, and the main metal minerals are iron, vanadium, copper, gold, cobalt, which provide guarantee the development of local steel industry. The local manufacturers are mainly dominated iron and steel, special-purpose vehicles, high-grade cardboard, new process carbon black, electronic materials, biomedical, textile clothing, green food. Ma'anshan Iron \& Steel Group is a large-scale steel joint enterprise and an important steel production base, as well as one of the largest industrial enterprises in Anhui Province. Geographical location of the study area is shown in Figure 1.

\section{Sampling sites and sample collection}

According to the urban road planning of the study area, the vehicle design speed of the trunk roads is $60 \mathrm{~km} / \mathrm{h}$, the number of vehicle lanes is $5 \sim 8$, and the width of the road is $45 \sim 55 \mathrm{~m}$. The design speed of motor vehicles on the sub-trunk roads is $40 \mathrm{~km} / \mathrm{h}$, the number of motor vehicle lanes is $4 \sim 6$, and the width of the road is $40 \sim 50 \mathrm{~m}$. As for the 
branch roads, the design speed of motor vehicles is $30 \mathrm{~km} / \mathrm{h}$, the number of motor vehicle lanes is $3 \sim 4$, and the width of the road is $15 \sim 30 \mathrm{~m}$. Before sampling, the trunk roads, sub-trunk roads and branch roads in Ma'anshan city are divided according to the geographical location and the flow of motor vehicles. The trunk road is the main road connecting the main urban districts, mainly including Huolishan Avenue, Jiangdong Avenue, Cihuher Road, Jiuhua Road, Yinshan Road, Yushan Road and the railway line crossing the city. The sub-trunk road is a large number of general traffic roads in the city, which coordinates with the trunk road to form the urban trunk roads network, and plays the role of connecting various parts and distributing traffic, mainly including Hongqi Road, Jiashan Road, Huayu Road, Pingshan Road, Kangle Road. The branch road is an important part of the road system, mainly undertaking short-distance traffic, including Hunan West Road, Jiuhua West Road, Park Road, Xiyuan Road, Pinghu Road, Yucai Road and so on.

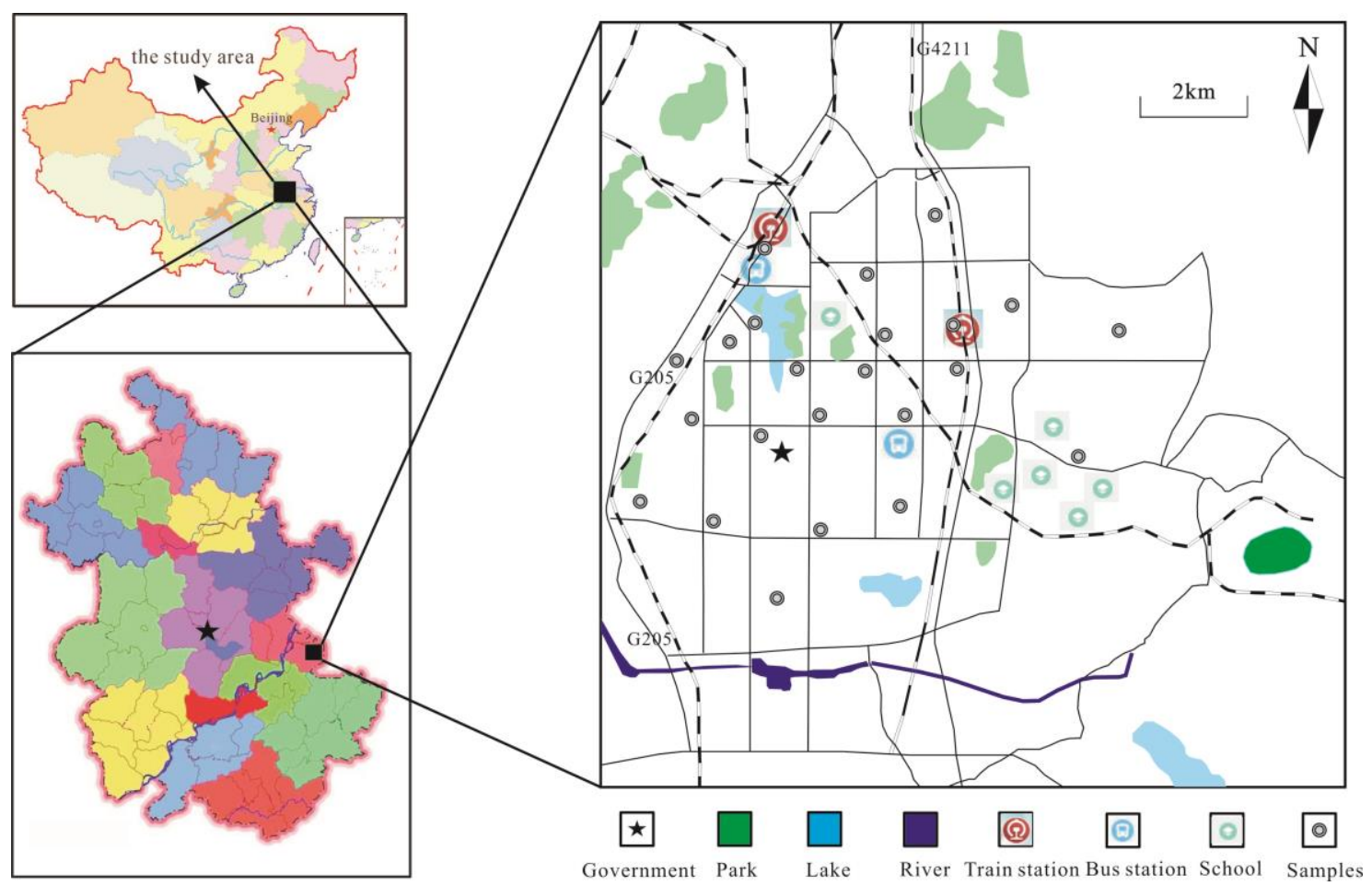

Figure 1. Geographical location and sampling distribution of the study area

In this study, samples collection was performed in December, 2015. Plant mulch and topsoil were removed before sample collection, and the sampling depth is $15 \mathrm{~cm}$. For each soil sample, five sub-samples were collected from different cells within a grid of approximately $5 \mathrm{~m}^{2}$ to form a composite sample to enhance the representativeness of the sample for each sampling site. The samples were stored in polyethylene packages that were transported back to the lab for chemical analysis. The samples were numbered sequentially on the bag. At the same time, GPS was used to determine the location of each sample point. A total of 22 surface soil samples were collected, including 11 trunk roads, 6 sub-trunk roads and 5 branch roads. Soil samples were firstly air-dried in the natural condition, sifted to remove stone and plant root debris, then ground to pass through a 200 -mesh sieve. 


\section{Experimental method}

(1) The authors weighed $0.1 \mathrm{~g}$ soil powder by electronic balance scale and put the soil into a tetrafluoroethylene digestion tank. Besides, $1 \mathrm{~mL}$ concentrated nitric acid, and $1 \mathrm{~mL}$ hydrofluoric acid is subsequently added. The authors put the sealed digestion tank in the steel sleeve, tightened the lid, and put it into the oven $\left(190^{\circ} \mathrm{C}\right)$ to heat for $20 \mathrm{~h}$. Then take the steel sleeve out of the oven for cooling, take out the digestion tank, heat it on a hot plate $\left(140^{\circ} \mathrm{C}\right)$ to near dry, add $4 \mathrm{~mL}$ concentrated nitric acid and $4 \mathrm{~mL}$ of deionized water. Then put the digestion tank into the steel sleeve, tighten the lid, put it in the oven at $150{ }^{\circ} \mathrm{C}$ for $2 \mathrm{~h}$, take out the steel can for cooling. After cooling, remove the digestion tank, transfer the liquid from the digestion tank into a $100 \mathrm{~mL}$ volumetric bottle, and wash the polytetrafluoroethylene with a certain amount of deionized water for 2 to 3 times. All the washing liquid is poured into the volumetric flask. Finally, the nitric acid solution was prepared, in which concentrated nitric acid $2 \mathrm{~mL}$ and deionized water $98 \mathrm{~mL}$ were used to titrate the volumetric flask.

(2) Using ICP-AES to determine the volume of solution in a volumetric flask, the internal standard of the element was selected, and the calibration curve was drawn. The concentration in the sample solution was calculated by regression equation to determine the heavy metal element content of the soil.

The above analysis and test were carried out at the Engineering Research Center of Coal Exploration, Anhui Province, China.

\section{Analysis methods}

\section{Geoaccumulation index}

The geoaccumulation index, also known as the Muller index, was proposed by German scientist Muller and developed in Europe as a quantitative index to study heavy metal pollution in sediments and other substances. The index of geoaccumulation $\left(I_{\text {geo }}\right)$ ensures the assessment of contamination degrees by comparing the current and preindustrial concentrations (Muller, 1969), and is calculated as follows.

$$
I=\log _{2}\left[C_{n} / K B_{n}\right]
$$

In Equation 1, $C_{n}$ means the measured content of the element in the sediment; $B_{n}$ represents the geochemical background value; and $K$ is the coefficient obtained by considering the variation of the background value that may be caused by the rocks differences in different places (in general, the $K$ value is 1.5). Moreover, the geoaccumulation index is classified as Table 1. This method takes into account not only human-made pollution factors and environmental geochemical background values but also takes into account the factors that may change background values due to natural diagenesis, which makes up for the shortcomings of other evaluation methods effectively (Jia, et al., 2009; Chai, et al., 2006)

\section{Potential ecological risk index}

Potential ecological risk index is a method for evaluating the pollution degree of heavy metals in soil or sediments and their potential ecological hazards. The potential ecological risk index can calculate as follows. 


$$
\begin{gathered}
C_{f}^{i}=C_{s}^{i} / C_{n}^{i} \\
E_{r}^{i}=T_{r}^{i} \times C_{f}^{i} \\
R I=\sum_{i=1}^{n} E_{r}^{i}
\end{gathered}
$$

In Equation 2, $C_{f}^{i}$ means the enrichment coefficient of heavy metal; $C_{s}^{i}$ means the concentration of heavy metal in the sample; $C_{n}^{i}$ means the reference value, generally taking the national or local environmental standard value in soil as the reference value (Fan et al., 2010); In Equation 3, $E_{r}^{i}$ means the potential ecological hazard coefficient of individual; $T_{r}^{i}$ means the toxicity response coefficient of heavy metal, the toxicity response coefficients were $\mathrm{Cd}=30>\mathrm{As}=10>\mathrm{Pb}=\mathrm{Co}=5>\mathrm{Cr}=2>\mathrm{Mn}=1$ (Aiuppa, et al., 2003; Armagan, et al., 2008), respectively; In Equation 4, RI means the potential of ecological risk of multiple metals. The classification criteria of heavy metals potential ecological risk index are listed in Table 2.

Table 1. Classification of index of geoaccumulation

\begin{tabular}{c|c|c}
\hline $\boldsymbol{I}_{\text {geo }}$ & Classification & Degree of pollution \\
\hline $5<I_{g e o} \leq_{10}$ & 6 & Extremely serious pollution \\
$4<I_{g e o} \leq_{5}$ & 5 & Strong-extreme pollution \\
$3<I_{g e o} \leq_{4}$ & 4 & Strong pollution \\
$2<I_{g e o} \leq_{3}$ & 3 & Medium-strong pollution \\
$1<I_{g e o} \leq_{2}$ & 2 & Medium pollution \\
$0<I_{g e o} \leq_{1}$ & 1 & Light pollution \\
$I_{g e o} \leq 0$ & 0 & No pollution \\
\hline
\end{tabular}

Table 2. Ranking standard of potential ecological risk hazards

\begin{tabular}{c|c|c|c}
\hline$E_{r}^{i}$ & Single ecological hazard & RI & Overall ecological hazard \\
\hline$<40$ & Low & $<150$ & Low \\
$40 \sim 80$ & Moderate & $150 \sim 300$ & Moderate \\
$80 \sim 160$ & Heavier & $300 \sim 600$ & Heavy \\
$160 \sim 320$ & Heavy & $>600$ & Serious \\
$>320$ & Serious & & \\
\hline
\end{tabular}

This method not only considers the content of heavy metals in soil, but also considers the migration rule of toxicity of heavy metals in soil, the sensitivity to heavy metal pollution, and the difference of background value of heavy metals, eliminating the influence of regional differences. The degree of potential ecological risk of heavy metals classified reflects the characteristics of bioavailability, relative contribution, spatial differences and so on. Generally, potential ecological risk index is a comprehensive indicator reflecting the potential impact of heavy metals on the ecological environment (Fan et al., 2010). 


\section{Multivariate statistical analysis}

Multivariate statistical analysis is a method of using mathematical statistics to study multivariate problems. It includes regression analysis, discriminant analysis, cluster analysis, principal component analysis, factor analysis, correspondence analysis and so on. It has been widely applied in education, medicine, economics, environmental science and other disciplines. Multivariable statistical analysis provides an alternative method to identify pollution sources, and many scholars use this method to identify the pollution sources of soil or sediment (Aiuppa, et al., 2003; Armagan, et al., 2008; Reisenhofer, et al., 1996; Sun, et al., 2012).

Factor analysis uses a few factors to describe the relationship between multiple indicators, several same-class variables with relatively close correlations with each type of variable becoming a factor, and fewer factors reflecting most of the original information (Zhang, 2004). The general steps are summarized as follows: (1) standardizing raw data, which does not change the correlation coefficients between variables, and eliminate the influence of different variables dimension; which not change the correlation coefficient between variables, on the contrary, it can eliminate the influence of the dimension of different variables. (2) calculating the correlation coefficient matrix of the normalized data and its corresponding eigenvalues and eigenvectors; (3) using the maximum variance method for orthogonal rotation. This process can make the factor load polarized, which easy to find the information represented by the factor; (4) determining the number of factors, calculating the score of factors, and making corresponding statistical analysis.

Cluster analysis is a simple multivariate analysis method that classifies the research objects according to their characteristics (Zhang, 2004). The basic idea of cluster analysis is to use quantitative statistical analysis method to find some statistics that can measure the degree of affinity between samples or variables. Subsequently, based on these statistics, some samples (or variables) with greater similarity are aggregated into one group and others (or variables) are aggregated into another group.

The multivariate statistical analysis methods mentioned above are all completed by International Business Machines Corporation (IBM) SPSS software. IBM SPSS is a software product and related service program developed by IBM for statistical analysis, data mining, predictive analysis, and decision support tasks. It has been applied to various fields of natural science, technological science, and social science.

\section{Visualization analysis}

SigmaPlot is an advanced statistical analysis and scientific drawing software developed by Systat Software Company. The software integrates graphics drawing and data analysis. It has been applied to medicine, life sciences, engineering and environmental sciences due to its simple operation and high efficiency. In this study, SigmaPlot software (version 12.5) was used to construct a three-dimensional model of the spatial distribution of heavy metals in the soil of Ma' anshan city of Anhui Province, China.

\section{Results}

\section{Content characteristics of heavy metals}

The statistical analysis results of heavy metals in both sides along the road in Ma'anshan city of China are shown in Table 3, and the statistical analysis of the data was performed by 
IBM SPSS statistic software (version 19). According to Table 1, the contents of soil heavy metals in this area varied in a certain range. Among them, $\mathrm{Pb}$ content ranged from 193 to $711 \mathrm{ug} / \mathrm{g}$ (average $463 \mathrm{ug} / \mathrm{g}$ ); Cd content ranged from 6.8 to $22.25 \mathrm{ug} / \mathrm{g}$ (average $12.55 \mathrm{ug} / \mathrm{g}$ ); Co content ranged from 284 to $395 \mathrm{ug} / \mathrm{g}$ (average $349 \mathrm{ug} / \mathrm{g}$ ); As content ranged from 2.25 to $63.85 \mathrm{ug} / \mathrm{g}$ (average $49.21 \mathrm{ug} / \mathrm{g}$ ); Mn content ranged from 298 to $717 \mathrm{ug} / \mathrm{g}$ (average $467 \mathrm{ug} / \mathrm{g}$ ); and $\mathrm{Cr}$ content ranged from 3.05 to $253 \mathrm{ug} / \mathrm{g}$ (average $85.19 \mathrm{ug} / \mathrm{g}$ ), respectively. The contents following the order of $\mathrm{Mn}>\mathrm{Pb}>\mathrm{Co}>\mathrm{Cr}>\mathrm{As}>\mathrm{Cd}$.

Table 3. Statistical analysis of heavy metals in soils (ug/g)

\begin{tabular}{c|c|c|c|c|c|c}
\hline & Pb & Cd & Co & As & Mn & Cr \\
\hline Minimum value & 193 & 6.8 & 284 & 2.25 & 298 & 3.05 \\
Maximum value & 711 & 22.25 & 395 & 63.85 & 717 & 253 \\
Mean value & 463 & 12.55 & 349 & 49.21 & 467 & 85.19 \\
Standard deviation & 168 & 4.94 & 34.11 & 15.55 & 119 & 84.31 \\
Variance & 28285 & 24.44 & 1164 & 241.75 & 14126 & 7108 \\
Coefficient of variation (CV) & 0.36 & 0.39 & 0.1 & 0.32 & 0.25 & 0.99 \\
Skewness & -0.013 & 0.986 & -0.615 & -2.189 & 1.141 & 0.825 \\
Kurtosis & -1.266 & 1.13 & -0.593 & 5.77 & 0.413 & 0.433 \\
(Liu, 2012) & 24.43 & 0.264 & - & 10.553 & - & 86.4 \\
Soil background value Ma'anshan & & & & & & \\
Soil background value in Anhui & 26.6 & 0.07 & 16.3 & 9 & 530 & 66.5 \\
(Environmental Monitoring of China, 1990) & & & & & & \\
Nationals soil background value & 26 & 0.08 & 12.7 & 11.2 & 583 & 61 \\
(Environmental Monitoring of China, 1990) & & & & & \\
\hline
\end{tabular}

Coefficient of variation ( $\mathrm{CV}$, represents the ratio of the standard deviation to the mean) is an index that can be used for identifying the anthropogenic contribution degree for pollution in environmental studies (Sarkar, et al., 2010; Sun, et al., 2017), previous studies revealed that when $\mathrm{CV}<0.10$ and $>0.90$ mean low and high anthropogenic contributions, respectively. In this study, the CV of the elements in the study area are following in the turn: $\mathrm{Cr}>\mathrm{Cd}>\mathrm{Pb}>\mathrm{As}>\mathrm{Mn}>\mathrm{Co}$, and $\mathrm{Cr}$ reached 0.99, which was a strong variation, while $\mathrm{Mn}, \mathrm{Pb}, \mathrm{Co}, \mathrm{Cr}$, As and $\mathrm{Cd}$ were relatively low $(<0.40)$. The results indicate that anthropogenic activities have probably influenced the soil to a certain degree.

Figure 2 shows the distribution of heavy metal elements in different types of road. The contents of $\mathrm{Pb}, \mathrm{Co}$ and $\mathrm{Mn}$ in the soils on both sides of trunk roads, sub-trunk roads and branch roads are higher and its differences are smaller, while the contents of $\mathrm{Cd}$, As and $\mathrm{Cr}$ are relatively lower. The contents of $\mathrm{Cr}$ in sub-trunks road are much lower than those in trunks road and branch road.

\section{Pollution assessment}

In this study, Ma'anshan City soil background value, Anhui Province soil background value and Chinese national soil background value were selected value for reference (Table 3). Geo-accumulation index analysis on both sides of different roads in Ma'anshan urban area was conducted, and the results show in Table 4 and Figure 3, Igeo1, $I_{g e o-2}$ and $I_{g e o-3}$ represent the geoaccumulation indexes calculated by the soil background values of Ma'anshan city, Anhui Province and Chinese, respectively. 


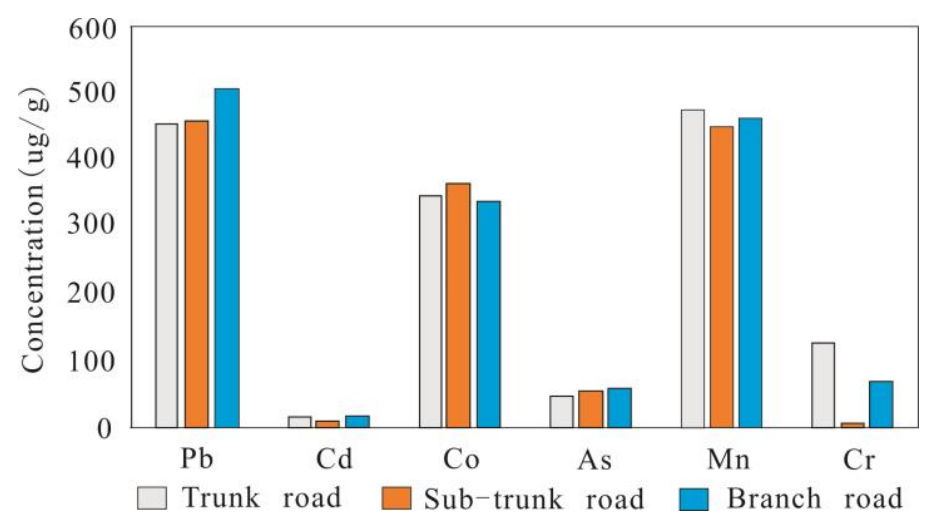

Figure 2. Distribution of heavy metal elements in different types of road

Table 4. Soil heavy metals in different roads on both sides of the geo-accumulation index

\begin{tabular}{c|c|c|c|c|c|c|c|c|c}
\hline & $\begin{array}{c}\text { Trunk } \\
\text { roads }\end{array}$ & $\begin{array}{c}\text { Sub-trunk } \\
\text { roads }\end{array}$ & $\begin{array}{c}\text { Branch } \\
\text { roads }\end{array}$ & $\begin{array}{c}\text { Trunk } \\
\text { roads }\end{array}$ & $\begin{array}{c}\text { Sub-trunk } \\
\text { roads }\end{array}$ & $\begin{array}{c}\text { Branch } \\
\text { roads }\end{array}$ & $\begin{array}{c}\text { Trunk } \\
\text { roads }\end{array}$ & $\begin{array}{c}\text { Sub-trunk } \\
\text { roads }\end{array}$ & $\begin{array}{c}\text { Branch } \\
\text { roads }\end{array}$ \\
\hline & \multicolumn{7}{|c|}{$I_{\text {geo- }-2}$} \\
$\mathrm{~Pb}$ & 3.63 & 3.64 & 3.78 & 3.51 & 3.52 & 3.66 & 3.54 & 3.55 & 3.69 \\
$\mathrm{Cd}$ & 5.23 & 4.45 & 5.23 & 7.15 & 6.36 & 7.14 & 6.96 & 6.17 & 6.95 \\
$\mathrm{Co}$ & - & - & - & 3.82 & 3.90 & 3.79 & 4.18 & 4.26 & 4.15 \\
$\mathrm{As}$ & 1.53 & 1.76 & 1.81 & 1.76 & 1.99 & 2.04 & 1.45 & 1.67 & 1.72 \\
$\mathrm{Mn}$ & - & - & - & -0.74 & -0.83 & -0.79 & -0.88 & -0.96 & -0.92 \\
$\mathrm{Cr}$ & -0.06 & -4.54 & -0.97 & 0.32 & -4.16 & -0.59 & 0.45 & -4.04 & -0.47 \\
\hline
\end{tabular}

According to Table 4, no matter which soil background value is taken as reference, soil heavy metals on both sides of urban trunk roads, sub-trunk roads and branch roads have a certain degree of pollution. The $\mathrm{Cr}$ and $\mathrm{Mn}$ element are non-polluting in the branch roads and the secondary trunk roads. For the trunk roads, if we refer to the soil background value of Ma'anshan City, $\mathrm{Cr}$ is non-polluting, if we compare with Anhui Province soil background value and the national soil background value, $\mathrm{Cr}$ belongs to mildly polluted. It indicates that the $\mathrm{Mn}$ element has not been polluted, $\mathrm{Cr}$ element has not been polluted or intensively polluted, and the overall condition is good. $\mathrm{Co}$ and $\mathrm{Pb}$ were strong pollutions, and $\mathrm{Cd}$ was a strong-extremely pollution level in the soil samples on both sides of the urban road in Ma'anshan City.

\section{Risk assessment}

The potential ecological risk index of heavy metals pollution in soils on both sides of different roads in Ma'anshan urban area is shown in Table 5. According to Table 5, the potential ecological hazard coefficients of each element follow the order of $\mathrm{Cd}>\mathrm{Co}>\mathrm{Pb}>\mathrm{As}>\mathrm{Cr}>\mathrm{Mn}$, which is consistent with the results of the geoaccumulation index method. Among them, $\mathrm{Cd}$ reached a severe degree of ecological risk, $\mathrm{Pb}, \mathrm{Co}$ was a relatively severe degree of ecological risk, As was a moderate degree of ecological risk, $\mathrm{Mn}, \mathrm{Cr}$ was a low degree of ecological risk. Besides, for the overall potential ecological hazard index (RI), the ecological risk of the sub-trunk road is lower than that of the trunk road and the branch road, but they also have reached the level of potential severe ecological risk. Therefore, the soil heavy metal pollution on both sides 
of the road in Ma'anshan city is a potential severe ecological hazard, and even $\mathrm{Pb}, \mathrm{Co}$ has reached a relatively severe ecological risk. Therefore, in the process of soil environmental treatment in the future, we should strengthen the management of $\mathrm{Cd}, \mathrm{Pb}$ and Co.

Table 5. Potential ecological risk index of heavy metals on both sides of the road

\begin{tabular}{|c|c|c|c|c|c|c|c|}
\hline & \multicolumn{6}{|c|}{$E_{r}^{i}$} & \multirow{2}{*}{ RI } \\
\hline & $\mathbf{P b}$ & Cd & Co & As & Mn & $\mathrm{Cr}$ & \\
\hline Trunk roads & 87.51 & 5592 & 136 & 40.94 & 0.82 & 4.09 & 5861 \\
\hline Sub-trunk roads & 88.02 & 3238 & 143.4 & 47.87 & 0.77 & 0.18 & 3518 \\
\hline Branch roads & 97.11 & 5569 & 133.3 & 49.53 & 0.79 & 2.17 & 5852 \\
\hline
\end{tabular}

\section{Discussion}

From the previous analysis, we can find that there is an interesting phenomenon here, that is, in the soil on both sides of the road in the study area, the concentration of heavy metals in the branch road is higher than that in the sub-trunk road, or even similar to that in the trunk road. The main reason we consider is that the traffic conditions of the branch roads are not as good as those of the main and secondary roads. According to China Urban Road Engineering Design Code (Ministry of Housing and Urban-Rural Construction of the People's Republic of China, 2016), the width of branches is generally 15-20 m, while the width of sub-trunk and trunk roads can reach 40-55 m, which directly determines the speed of motor vehicles on the road. Generally speaking, the speed of branches is lower than $30 \mathrm{~km} / \mathrm{h}$ or even lower. However, the sub-trunk road can reach $30-50 \mathrm{~km} / \mathrm{h}$ and the trunk road can reach $60 \mathrm{~km} / \mathrm{h}$. Therefore, in the process of driving on the branch road, automobiles are bound to brake frequently and even start their cars. Brake, brake and tire wear will inevitably lead to the increase of heavy metal content, which makes the heavy metal content of branch road higher than that of subtrunk road.

In addition, soil heavy metals are not only related to the background value of bedrock (or parent material), but also influenced by the mode and intensity of human activities. According to the analysis above, soil heavy metals in this area are polluted to some extent. In order to identify pollution sources effectively, factor analysis was carried out for heavy metals. According to the eigenvalue and cumulative variance contribution rate, two factors were extracted (Table 6 ). The explanations of variance were $49.512 \%$, $36.764 \%$, respectively, and the complete explanations of cumulative variance were $86.277 \%$. For the sake of understanding the information represented by each principal component, the factors are rotated using the maximum variance method (Table 6). According to Table 6 and Figure 3, PC1 is controlled by $\mathrm{Cd}, \mathrm{As}$, and $\mathrm{Cr}$, and PC2 is controlled by $\mathrm{Co}, \mathrm{Mn}$ and $\mathrm{Pb}$.

Xie (2010) holds that Cd mainly originates from industrial activities, such as smelting, electroplating, batteries, metal processing and so on. The sources of $\mathrm{Cd}$ in soil are mainly attributed to natural and human activities. The former mainly comes from the background values of rocks and soils, while the latter mainly comes from industrial "three wastes" (waste water, waste gas, and waste residue) and large amounts of Cdcontaining fertilizers. Industrial waste gas is the main source of air Cd pollution. The content of $\mathrm{Cd}$ in the air of remote areas is generally lower than $1.0 \mathrm{pg} / \mathrm{mL}$, but the 
concentration of $\mathrm{Cd}$ in the atmosphere around industrial areas is higher (Zeng, et al., 2005). Dry and wet deposition of $\mathrm{Cd}$ contaminants in the atmosphere is also a significant import cause of soil $\mathrm{Cd}$ pollution. Higher concentrations of $\mathrm{Cd}$ can enter the soil through rainfall or sedimentation. Plants absorb some of $\mathrm{Cd}$ and cause pollution, and the remained $\mathrm{Cd}$ accumulates in the soil. Combining the actual situation of iron and steel industry in Ma'anshan city and the spatial characteristics of $\mathrm{Cd}$, As and $\mathrm{Cr}$ (Fig. 4), it can be concluded that factor 1 is affected by industry. Lead is a tracer element of automobile exhaust emissions (Lv, et al., 2013). In general, The background value of a lead in the environment is very low, and lead is mainly derived from tetraethyl lead anti-explosive agent in gasoline. However, the gasoline combustion process can be decomposed to produce inorganic lead and lead-containing oxides. After being discharged from the vehicle exhaust, it settles in the soil on both sides of roads through the atmosphere. According to this, PC2 can be expressed as the impact of road traffic. So far, it can be concluded that the primary sources of $\mathrm{Cd}$, As and $\mathrm{Cr}$ in soils on both sides of urban roads are industrial "three wastes", while the emission of urban traffic exhaust and the wear of urban tires are the essential sources of $\mathrm{Pb}, \mathrm{Mn}$ and $\mathrm{Co}$ pollution in soil samples.

Table 6. Total variance explained and component matrices for heavy metal contents

\begin{tabular}{|c|c|c|c|c|c|c|c|c|c|}
\hline \multirow[t]{2}{*}{ Components } & \multicolumn{3}{|c|}{ Initial Eigenvalues } & \multicolumn{3}{|c|}{ Extracting sums of squares } & \multicolumn{3}{|c|}{ Extraction sums of squared loadings } \\
\hline & Total & $\%$ of variance & Cumulative \% & Total & $\%$ of variance & Cumulative \% & Total & $\%$ of variance & Cumulative \% \\
\hline 1 & 3.007 & 50.112 & 50.112 & 3.007 & 50.112 & 50.112 & 2.971 & 49.512 & 49.512 \\
\hline \multirow[t]{9}{*}{2} & 2.17 & 36.165 & 86.277 & 2.17 & 36.165 & 86.277 & 2.206 & 36.764 & 86.277 \\
\hline & \multicolumn{3}{|c|}{ Component matrix } & & & \multicolumn{3}{|c|}{ Rotated component matrix } & \\
\hline & & $\mathrm{PC} 1$ & PC2 & & & & $\mathrm{PC} 1$ & $\mathrm{PC} 2$ & \\
\hline & $\mathrm{Pb}$ & -0.313 & -0.84 & & & $\mathrm{~Pb}$ & -0.133 & -0.887 & \\
\hline & $\mathrm{Cd}$ & 0.979 & 0.067 & & & $\mathrm{Cd}$ & 0.944 & 0.268 & \\
\hline & Co & -0.329 & 0.924 & & & $\mathrm{Co}$ & -0.513 & 0.835 & \\
\hline & As & 0.865 & -0.257 & & & As & 0.9 & -0.072 & \\
\hline & $\mathrm{Mn}$ & 0.447 & 0.723 & & & $\mathrm{Mn}$ & 0.288 & 0.8 & \\
\hline & $\mathrm{Cr}$ & 0.945 & -0.133 & & & $\mathrm{Cr}$ & 0.952 & 0.066 & \\
\hline
\end{tabular}

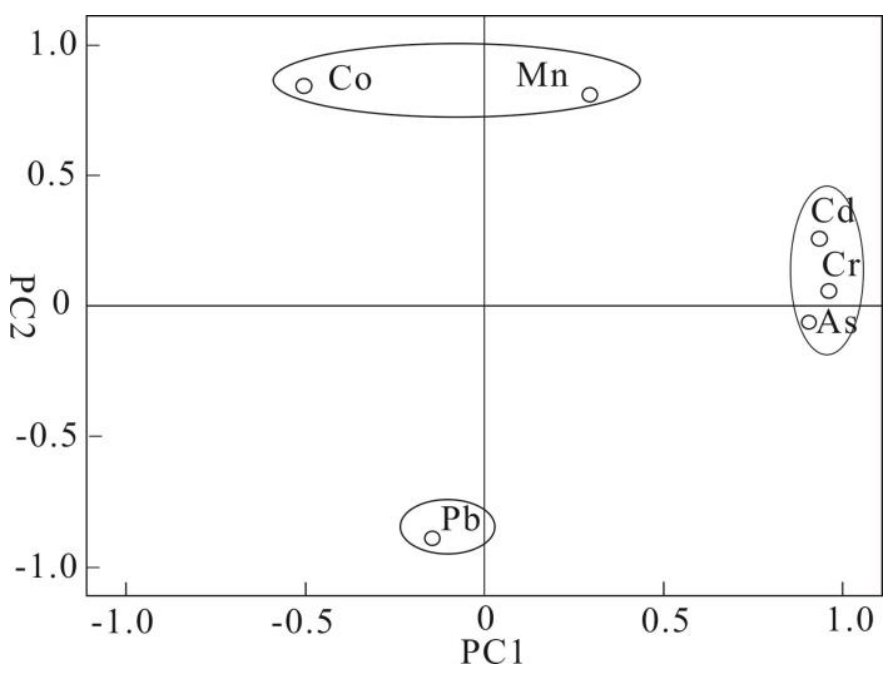

Figure 3. Factor loading of soil heavy metal sources 


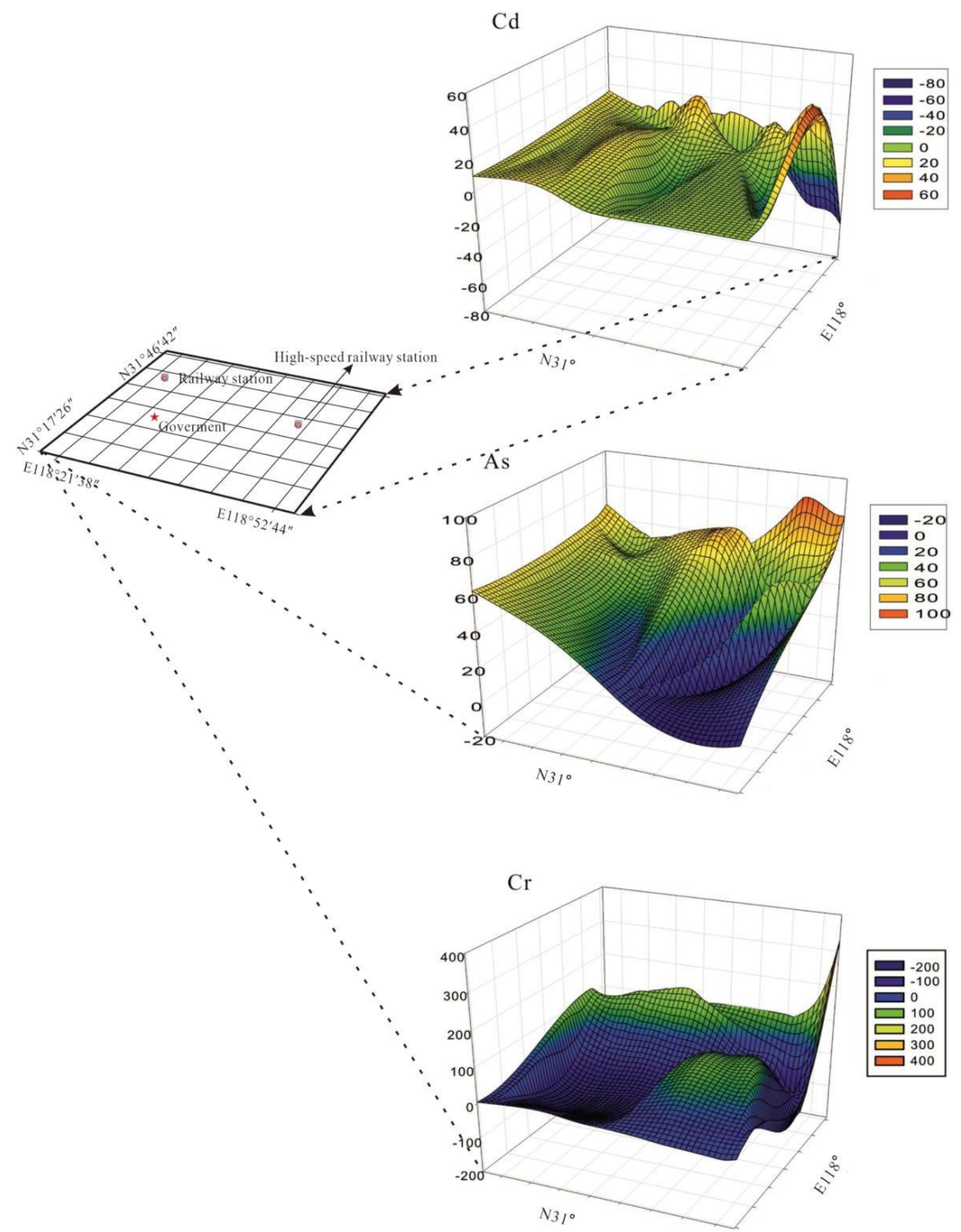

Figure 4. Spatial distribution characteristics of $\mathrm{Cd}$, As and $\mathrm{Cr}$

In order to verify the accuracy of the factor analysis method, the soil heavy metal elements were clustered (Fig. 5). Clustering results are ideal, and can be divided into three categories: $\mathrm{Cd}-\mathrm{Cr}-\mathrm{As}, \mathrm{Co}-\mathrm{Mn}, \mathrm{Pb}$ clustered into a single group, consistent with the results of factor analysis. 


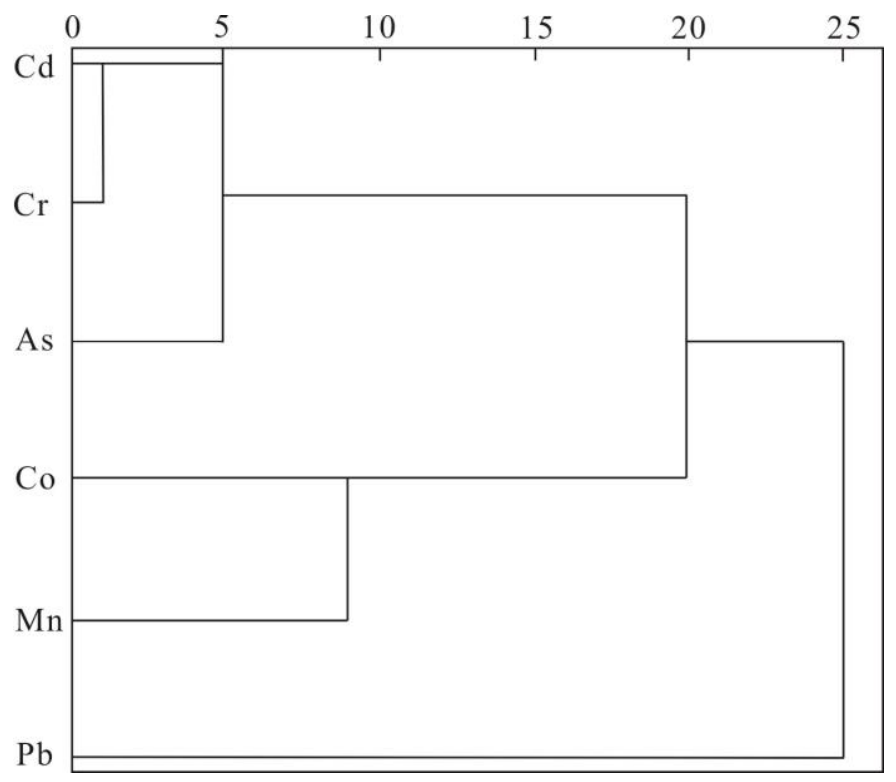

Figure 5. Cluster analysis of soil heavy metals

\section{Conclusion}

The contents of heavy metals in soils on both sides of roads in Ma'anshan city changed within a certain range, and the average contents were following in the order of $\mathrm{Mn}>\mathrm{Pb}>\mathrm{Co}>\mathrm{Cr}>\mathrm{As}>\mathrm{Cd}$ from large to small. For the soils on both sides of different types of roads, the content of $\mathrm{Pb}, \mathrm{Co}$ and $\mathrm{Mn}$ is higher than that of $\mathrm{Cd}$, As and $\mathrm{Cr}$, and the concentrations of $\mathrm{Cr}$ in sub-trunk roads is lower than that of trunk roads and branch roads.

Pollution assessment showed that heavy metals in the soil on both sides of urban trunk roads, sub-trunk roads and branch roads were polluted to a certain extent. $\mathrm{Mn}$ is no pollution; $\mathrm{Cr}$ element had not been polluted or intensity pollution, the overall situation was good; $\mathrm{Co}, \mathrm{Pb}$ belonged to strong pollution level; $\mathrm{Cd}$ belonged to the severe pollution level.

The risk assessment showed that $\mathrm{Cd}$ was a severe ecological risk, $\mathrm{Pb}$ and $\mathrm{Co}$ was a severe ecological risk, As was a moderate ecological risk, $\mathrm{Mn}$ and $\mathrm{Cr}$ was a low ecological risk. According to the total potential ecological hazard index, the ecological risk of the sub-trunk road is lower than that of the main road and the sub-trunk road, which has reached a severe potential ecological risk degree. In the future soil quality management process, it is particularly necessary to strengthen the management of cadmium, lead and cobalt pollution.

Two principal components of the six heavy metal elements have been extracted by factor analysis. Combining with the spatial distribution characteristics of heavy metals, two sources have been identified, PC1 (Pb, Mn, Co) and PC2 (Cd, As, Cr). The former are contributed mainly by industrial pollution, while the latter are primarily influenced by traffic pollution.

\section{Recommendations}

Taking Ma'anshan City, Anhui Province as an example, this paper discussed the pollution status and sources of heavy metals in soil along the trunk roads, sub-trunk 
roads and branch roads of the city, which has a certain practical significance for the prevention and control of heavy metals pollution in urban soil. In the future research, we need to pay more attention to the study of heavy metal pollution level and occurrence in road ash layer, rainfall and other media. We can even make a comparative study of the heavy metal pollution in the soil on both sides of different roads in industrial and non-industrial cities, so as to explore the impact of different types of cities and different specifications of road traffic activities on the distribution of heavy metals, and evaluate their pollution, so as to provide theoretical support for the prevention and control of heavy metal pollution.

Acknowledgments. This work was financially supported by National Natural Science Foundation of China (No. 51474008), Excellent top talent cultivation project in higher education institutions in Anhui Province (No. gxyq2019151), Key Natural Science Research Projects of Universities in Anhui Province (No. KJ2019A1281), Research Project of Wanjiang University of Technology (No. WG18026).

\section{REFERENCES}

[1] Afanasyeva, L. V., Ayushina, T. A.. (2019): Accumulation of heavy metals and biochemical responses in Siberian larch needles in urban area. - Ecotoxicology 28(5): 578-588.

[2] Aiuppa, A., Bellomo, S., Brusca, L., D’Alessandro, W., Federico, C. (2003): Natural and anthropogenic factors affecting groundwater quality of an active volcano (Mt. Etna, Italy). - Applied Geochemistry 18(6): 863-882.

[3] Armagan, G., Turgut, C. (2008): Analysis of environmental pollution with multivariate statistical techniques. - Fresenius Environmental Bulletin 17(8): 978-984.

[4] Billah, M. M., Kokushi, E., Uno, S. (2019): Distribution, geochemical speciation, and bioavailable potencies of cadmium, copper, lead, and zinc in sediments from urban coastal environment in Osaka Bay, Japan. - Water Air Soil Pollut 230: 157. doi.org/10.1007/s11270-019-4196-8.

[5] Chai, S. W., Wen, Y. M., Zhang, Y. L., Zhao, J. F. (2006): Application of index of geoaccumulation to pollution evaluation of heavy metals in soil. - Journal of Tongji University (Natural Science) 34(12): 1657-1661.

[6] Environmental Monitoring of China (1990): Background Values of Soil Elements in China. - China Environmental Science Press, Beijing.

[7] Fan, S. X., Gan, Z. T., Li, M. J., Zhang, Z. Q., Zhou, Q. (2010): Progress of assessment methods of heavy metal pollution in soil. - Chinese Agricultural Science Bulletin 26(17): 310-315.

[8] Guo, G. H., Lei, M., Chen, T. B., Song, B., Li, X. Y. (2008): Effect of road traffic on heavy metals in road dusts and roadside soils. - Acta Scientiae Circumstantiae 28(10): 1937-1945.

[9] Hafeez, F., Zafar, N., Nazir, R., Javeed, H. M. R., Rizwan, M., Faridullah, et al. (2019): Assessment of flood-induced changes in soil heavy metal and nutrient status in Rajanpur, Pakistan. - Environmental Monitoring and Assessment 191(4).

[10] Hashim, M. A., Mukhopadhyay, S., Sahu, J. N. (2011): Remediation technologies for heavy metal contaminated groundwater. - Journal of Environmental Management 92(10): 2355-2388.

[11] Jia, Z., Zhou, H., Zhao, Z., Tao, S., Zhang, B., Zhao, L. (2000): The application of the index of geoaccumulation to evaluate heavy metal pollution in sediments in the Benxi section of the Taizi River. - Acta Scientiarum Naturalium Universitatis Pekinensis 36(4): 525-530. 
[12] Komendova, R., Jezek, S.. (2018): The distribution of platinum in the environment in large cities: a model study from Brno, Czech Republic. - International Journal of Environmental Science and Technology 16(7): 3109-3116.

[13] Liu, H. (2012): Research on Assessment of Heavy Metal Pollution in the Soil in Ma' Anshan Key Mining Area. - Hefei University of Technology, Hefei.

[14] Lv, J. S., Liu, Y., Zhang, Z. L. (2013): Factorial kriging and stepwise regression approach to identify environmental factors influencing spatial multi-scale variability of heavy metals in soils. - Journal of Hazardous Materials 261: 387-397.

[15] Ministry of Housing and Urban-Rural Construction of the People's Republic of China (2016): Code for Urban Road Engineering Design. - Ministry of Housing and UrbanRural Construction, China, pp. 1-93.

[16] Muller, G. (1969): Index of geoaccumulation in sediments of the Rhine River. - Journal of Geology 2(3): 109-118.

[17] Reisenhofer, E., Adami, G., Favretto, A. (1996): Heavy metals and nutrients in coastal, surface seawaters (Gulf of Trieste, northern Adriatic Sea): an environmental study by factor analysis. - Fresenius Journal of Analytical Chemistry 354(5-6): 729-734.

[18] Reza, S. K., Baruah, U., Singh, S. K., Das, T. H. (2015): Geostatistical and multivariate analysis of soil heavy metal contamination near coal mining area, northeastern India. Environmental Earth Sciences 73(9): 5425-5433.

[19] Sarkar, D., Datta, R., Hannigan, R. (2007): Concepts and Applications in Environmental Geochemistry. - Elsevier, Amsterdam.

[20] Sun, L. H., Gui, H. R., Xu, D. S., Huang, S. L. (2012): Heavy metal pollution in rural area of china: a case study of pond sediments from Sixian County, Northern Anhui Province. - Fresenius Environmental Bulletin 21(2): 263-268.

[21] Sun, L. H., Cheng, B. X., Chen, S. H. (2017): Trace metal concentrations in the river water near the urban area, a case study in Suzhou, northern Anhui province, China. Fresenius Environmental Bulletin 26(6): 4017.

[22] Sun, Z. B., Liu, B. J., Zhou, J., Hu, B. B., Meng, W. Q., Wang, Z. L. (2015): Heavy metals pollution and ecological risk assessment on urban street dust of Tianjin. Environmental Science \& Technology 38(8): 244-250.

[23] Xie, H. F., Fang, F., M., Wang, H. D. (2010): Research progress on heavy metal pollution in urban street dust. - Environmental Pollution and Control 32(5): 78-81.

[24] Zeng, Y. M., Mao, K. M., Li, Y. M. (2005): Damage of the cadmium (Cd) pollution in soil and its control. - Journal of Yunnan Agricultural University 20(3): 360-365.

[25] Zhang, W. T. (2004): SPSS Advanced Statistical Analysis Tutorial. - Higher Education Press, Beijing. 